\title{
CSF/serum albumin ratio in dementias: a cross-sectional study on 1861 patients
}

Tobias Skillbäck*a,b MD, Louise Delsing*a,c, Jane Synnergren ${ }^{\mathbf{c}}$ PhD, Niklas Mattsson ${ }^{\mathbf{d}, \mathbf{e}}$ MD, PhD, Shorena Janelidze ${ }^{\mathbf{d}} \mathrm{PhD}$, Katarina Nägga ${ }^{\mathbf{d}}$ MD, PhD, Lena Kilander ${ }^{\mathbf{f}}$ MD PhD, Ryan Hicks ${ }^{g}$ PhD, Anders Wimo ${ }^{\mathbf{h}, \mathbf{i}}$ MD, PhD, Bengt Winblad ${ }^{\mathbf{i}, \mathbf{j}}$ MD, PhD, Oskar Hansson $^{\mathbf{d}, \mathbf{e}}$ MD, PhD, Kaj Blennow ${ }^{\mathbf{a}, \mathbf{b}}$ MD, PhD, Maria Eriksdotter ${ }^{\mathbf{j}, \mathbf{k}}$ MD, PhD, Henrik Zetterberg ${ }^{\mathbf{a}, \mathbf{b}, \mathbf{l}, \mathbf{m}} \mathrm{MD}, \mathrm{PhD}$

*These authors contributed equally to this work

${ }^{a}$ Institute of Neuroscience and Physiology, Department of Neurochemistry, the Sahlgrenska Academy at the University of Gothenburg, Mölndal, Sweden

${ }^{\mathbf{b} C l i n i c a l ~ N e u r o c h e m i s t r y ~ L a b o r a t o r y, ~ S a h l g r e n s k a ~ U n i v e r s i t y ~ H o s p i t a l, ~ M o ̈ l n d a l, ~ S w e d e n ~}$

'Systems Biology Research Center, School of Bioscience, University of Skövde, Sweden

${ }^{\mathrm{d}}$ Clinical Memory Research Unit, Department of Clinical Sciences Malmö, Lund University, Malmö, Sweden.

'Department of Neurology, Skåne University Hospital, Lund, Sweden.

fDepartment of Public Health and Caring Sciences/Geriatrics, Uppsala University, Uppsala, Sweden

gDiscovery Sciences, IMED Biotech Unit, AstraZeneca, Mölndal, Sweden.

${ }^{\mathbf{h}}$ Centre for Research \& Development, Uppsala University/County Council of Gävleborg, Gävle, Sweden

iDepartment of Neurobiology, Care Sciences, and Society (NVS), Center for Alzheimer Research, Division for Neurogeriatrtics, Karolinska Institutet, Huddinge, Sweden

${ }^{j}$ Department Geriatric Medicine, Karolinska University Hospital, Huddinge, Sweden

${ }^{\mathbf{k}}$ Department of Neurobiology, Care Sciences, and Society (NVS), Center for Alzheimer Research, Division of Clinical Geriatrics, Karolinska Institutet, Huddinge, Sweden

'Department of Molecular Neuroscience, UCL Institute of Neurology, Queen Square, London WC1N 3BG, UK

${ }^{\mathrm{m}}$ UK Dementia Research Institute at UCL, London WC1N 3BG, UK.

\section{Corresponding author:}

Louise Delsing

Systems Biology Research Center, School of Bioscience,

University of Skövde,

Högskolevägen, Box 408

54128 Skövde

Sweden

Email: louise.delsing@his.se

Keywords: CSF/serum albumin ratio; Dementia; Blood brain barrier; Alzheimer's disease; 


\section{Abbreviations:}

AD - Alzheimer's disease

A $\beta 42$ - Amyloid beta 42

BBB - Blood brain barrier

CNS - Central nervous system

CSF - Cerebrospinal fluid

EAD - Early onset Alzheimer's disease

FTD - Frontotemporal dementia

LAD - Late onset Alzheimer's disease

LBD - Lewy body dementia

MIX - Mixed AD and vascular dementia

MMSE - Mini mental state examination

NFL - Neurofilament light protein

NOS - Dementia not otherwise specified

Other - Other dementia diagnoses

PDD - Parkinson's disease dementia

P-tau - Phosphorylated tau

SveDem - Swedish Dementia Registry

T-tau - Total tau

$\mathrm{VaD}$ - Vascular dementia

WM - White matter 


\begin{abstract}
A connection between dementias and blood-brain barrier (BBB) dysfunction has been suggested, but previous studies have yielded conflicting results. We examined CSF/serum albumin ratio in a large cohort of patients diagnosed with Alzheimer's disease (AD, early onset [EAD, $n=130]$, late onset $\mathrm{AD}$ [LAD, $n=666])$, vascular dementia $(\mathrm{VaD}, \mathrm{n}=255)$, mixed $\mathrm{AD}$ and $\mathrm{VaD}$ (MIX, $\mathrm{n}=362$ ), Lewy body dementia (DLB, $\mathrm{n}=50$ ), frontotemporal dementia (FTD, $n=56$ ), Parkinson's disease dementia (PDD, $n=23$ ), other dementias (Other, $n=48$ ) and dementia not otherwise specified (NOS, $\mathrm{n}=271$ ). We compared CSF/serum albumin ratio to two healthy control groups $(n=292, n=20)$, between dementia diagnoses, and tested biomarker associations. Patients in DLB, LAD, VaD, MIX, Other and NOS groups had higher $\mathrm{CSF} /$ serum albumin ratio than controls. CSF/serum albumin ratio correlated with CSF neurofilament light in LAD, MIX, VaD and Other, but not with AD biomarkers. Our data shows that BBB leakage is common in dementias. The lack of association between $\mathrm{CSF} /$ serum albumin ratio and $\mathrm{AD}$ biomarkers suggests that $\mathrm{BBB}$ dysfunction is not inherent to $\mathrm{AD}$ but might represent concomitant cerebrovascular pathology.
\end{abstract}




\section{Introduction}

Dementia is a major health concern with more than 47 million affected patients worldwide and an increasing prevalence as the population ages. The most common causes of dementia are Alzheimer's disease (AD) and vascular dementia (VaD) (Wimo et al., 2017). An increasing body of research suggests that there is a connection between dementia and vascular pathology (Nelson et al., 2016), including molecular and epidemiologic evidence that vascular disease is a risk factor for dementia (Beydoun et al., 2014, Hughes and Ganguli, 2009, Iadecola, 2013, McAleese et al., 2016, Wiesmann et al., 2013). Many risk factors for AD and reduced cognitive abilities, such as stroke, hypertension, hyperlipidemia, diabetes and atrial fibrillation, affect the vasculature (Gorelick, 2004, Hayden et al., 2006, Kilander et al., 1998, Kivipelto et al., 2001, Ott et al., 1996, Skoog et al., 1996). In addition, increased permeability of the blood brain barrier (BBB) has been indicated in several of these conditions (Hovsepyan et al., 2004, Hsu and Kanoski, 2014, Starr et al., 2003, Tang et al., 1992).

There is great diversity in the vascular mechanisms that may underlie dementia, including diffuse white matter lesions, hypoperfusion, oxidative stress and inflammation (Iadecola, 2013). Many of these have effects on the brain vasculature causing endothelial damage, BBB breakdown and activation of the innate immune response (McAleeseet al., 2016). BBB damage may lead to disruption of the tightly controlled metabolic balance between vascular and brain cells and suboptimal control of exposure of the brain tissue to blood-associated substances, which ultimately may result in demyelination, axonal loss and cognitive impairment (Fornari et al., 2012, Iadecola, 2013, Ryu et al., 2015). In the light of these findings, there is a need to further evaluate the contribution of BBB dysfunction in different dementias. 
The BBB is the interface between the blood and the brain, regulating the transport of molecules between the blood and the central nervous system (CNS). Its primary function is to maintain the tightly controlled microenvironment of the brain, which is a critical part in sustaining a healthy nervous system (Obermeier et al., 2013). A standard measure of BBB function in clinical laboratory practice is the CSF/serum albumin ratio (Tibbling et al., 1977). Proteins will pass from blood to CSF across the BBB at different rates, depending on their hydrodynamic radii, with passage of larger proteins being more restricted than that of smaller proteins (Felgenhauer and Renner, 1977). This limits the movement of albumin from blood to CSF. As albumin is not produced in the CNS, CSF/serum albumin ratio can be used to assess the integrity of the BBB (Reiber and Peter, 2001). There are other candidate methods for investigating BBB integrity. These include measurements of fluid biomarkers such as blood occludin (Pan et al., 2017) and other tight junction proteins (Sweeney et al., 2015), serum MMP-9 (Waubant et al., 1999), plasma fibrinogen (Bridges et al., 2014) and markers related to pericyte breakdown (Halliday et al., 2016), as well as non-fluid biomarker methods such as dynamic contrast-enhanced magnetic resonance imaging (MRI) (Montagne et al., 2015, Taheri et al., 2011, van de Haar et al., 2016). Although contrast-enhanced MRI can provide improved spatial and temporal resolution, CSF/serum albumin ratio has the advantage of being a readily available test in automated clinical chemistry analyzers that are standardized for routine use in general clinical laboratory practice around the world. It is also the only fluid biomarker that has been validated for clinical use.

Most studies investigating CSF/serum albumin ratio in dementia patients have included a relatively small number of individuals and have primarily focused on AD \{Elovaara, 1986 \#127;Wada, 1998 \#129;Wada, 1998 \#129;Farrall, 2009 \#133;Alafuzoff, 1983 \#126;Kay, 1987 \#135;Hampel, 1997 \#128;Blennow, 1990 \#132;Hermann, 2014 \#30\}. However, there is a more comprehensive study of CSF/serum albumin ratio in dementia patients focusing mainly 
on Creutzfeldt-Jakob disease $\{$ Karch, $2013 \# 213\}$. There have been conflicting reports as to whether $\mathrm{BBB}$ damage can be linked to $\mathrm{AD}$, and reports of higher incidence of $\mathrm{BBB}$ damage in AD compared to controls have been published (Elovaara et al., 1986, Farrall and Wardlaw, 2009, Janelidze et al., 2017, Skoog et al., 1998, Wada, 1998), as well as reports where no difference in BBB integrity compared to controls could be found (Alafuzoffet al., 1983, Blennowet al., 1990, Hampelet al., 1997, Kayet al., 1987). A recent meta-analysis suggests that there is no significant change in $\mathrm{CSF} /$ serum albumin ratio in $\mathrm{AD}$ (Olsson et al., 2016a). In animal models, most studies report that cerebrovascular changes and BBB alterations are part of the AD pathology (Blair et al., 2015, Gama Sosa et al., 2010, Giannoni et al., 2016, KumarSingh et al., 2005, Park et al., 2013), whilst one study reports no change in BBB permeability for several AD models (Bien-Ly et al., 2015).

Conflicting results have also been reported in studies of the prevalence of BBB damage in patients with VaD compared to AD (Alafuzoff et al., 1983, Blennow et al., 1990, Blennow et al., 1991, Farrall and Wardlaw, 2009, Skoog et al., 1998, Wada, 1998). Considering the contradictive findings in this area, we set out to investigate BBB integrity in a large population of dementia patients using data from the Swedish Dementia Registry (SveDem). We hypothesized that a subgroup of dementia patients have increased CSF/serum albumin ratio, as a marker of BBB dysfunction, and that this is partly linked to cerebrovascular disease. Since BBB integrity is tightly linked to the important homeostasis of the CNS, we also hypothesized that increased CSF/serum albumin ratio would be related to worse disease severity.

\section{Methods}

\subsection{Data sources and clinical criteria}

Two sources of patient information were combined and used for this study. The first was a 
complete set of archived data on all CSF/serum albumin ratios, A $\beta 42$, total tau (T-tau), phosphorylated tau (P-tau) and neurofilament light protein (NFL) measurements performed in clinical practice at the Mölndal site of the Sahlgrenska University Hospital, Sweden from January 1, 2005 to June 1, 2012. The inclusion criteria for this study were an age of sampling above 30, and a maximum of 24 months between dementia diagnosis and lumbar puncture.

The second source of data was the Swedish Dementia Registry, SveDem, which was started in May 2007 to improve the quality of the diagnostic workup, treatment and care for dementia patients throughout Sweden, and which presently covers $100 \%$ of all memory clinics and $75 \%$ of all primary care units in Sweden (Religa et al., 2015, SveDem, 2015). From SveDem information on clinical diagnoses, medications, date of diagnosis, and mini mental state examination (MMSE) scores were drawn. In SveDem, each patient is assigned to a single diagnosis group out of nine preset options in the report form: early onset $\mathrm{AD}(\mathrm{EAD},<65$ years of age), late onset $\mathrm{AD}(\mathrm{LAD},>65$ years of age) and vascular dementia $(\mathrm{VaD})$ according to ICD-10 (World Health Organization., 1993), FTD according to Manchester criteria (The Lund and Manchester Groups, 1994), dementia with Lewy bodies (DLB) according to McKeith criteria (McKeith et al., 2005), Parkinson's with dementia (PDD) according to Movement Disorder Society Task Force criteria (Martinez-Martin et al., 2011), mixed AD and vascular dementia (MIX), dementia not otherwise specified (dementia NOS) and a group for the collected remainders of named dementia diagnoses called "Other" (including for example, Creutzfeldt-Jakob disease, HIV-associated neurocognitive disorder and Huntington's disease).

Information from the two data sources was cross-referenced using the unique Swedish personal identity number. Multiple CSF analyses on the same individual were excluded and only the measurement closest to the date of diagnosis was left in the dataset. 1,861 individuals were matched between the CSF data file and SveDem and used for the analyses in this study. 
Reference data on the CSF/serum albumin ratio from healthy age matched control subjects without symptoms of cognitive dysfunction were obtained from two previously published sources from our laboratory. Data for 292 healthy controls (HC1) were obtained from a study conducted at the Memory Clinic of Skåne University Hospital in Malmö, Sweden (Janelidze et al., 2017) and data for 20 healthy controls (HC2) were obtained from a study conducted at a memory clinic in Falköping, Sweden (Johansson et al., 2011).

\subsection{Biochemical measurements}

All CSF analyses were performed in clinical practice by board-certified laboratory technicians using procedures accredited by the Swedish Board for Accreditation and Conformity Assessment (SWEDAC; the national accreditation body for laboratory medicine in Sweden). INNOTEST enzyme-linked immunosorbent assays were used to measure CSF T-tau, P-tau and A $\beta 42$ concentrations (Fujirebio, Ghent, Belgium). CSF NFL concentration was measured as previously described (Skillback et al., 2014). Serum and CSF albumin concentrations were measured by immunonephelometry on a Beckman Immage Immunochemistry system (Beckman Instruments, Beckman Coulter, Brea, CA, USA). The CSF/serum albumin ratio was calculated as CSF albumin (mg/L)/serum albumin (g/L). Longitudinal stability in the measurements over years was ascertained using an elaborate system of internal quality control samples and testing of incoming reagents and intra- and inter-day coefficients of variation were below $5 \%$.

All patients were classified as having either a presence or absence of a pathological $\mathrm{CSF} / \mathrm{serum}$ albumin ratio according to the clinical reference limits at the Sahlgrenska University hospital. The cutoffs used were $>6.8$ for study participants $30-45$ years of age and $>10.2$ for study participants $>45$ years of age. The AD group was further sub-classified into biochemically positive or negative AD according to IWG-2. Biochemically positive patients 
had low A $\beta 42$ and high T-tau or P-tau (Dubois et al., 2014). The following cutoffs were used: $\mathrm{A} \beta 42 \leq 550 \mathrm{pg} / \mathrm{mL}, \mathrm{T}$-tau $\geq 400 \mathrm{pg} / \mathrm{mL}, \mathrm{P}$-tau $>60 \mathrm{pg} / \mathrm{mL}$ for patients $<60$ years, and P-tau $>$ $80 \mathrm{pg} / \mathrm{mL}$ for patients $\geq 60$ years. When specified, the LAD, EAD and MIX groups were analyzed together as an AD group. Reporting clinicians were instructed to follow diagnostic guidelines as specified in ICD-10 to secure a unified basis for diagnosis (Sorbi et al., 2012).

2.3 Data analysis Age differences between groups were tested by Kruskal-Wallis analysis. $\mathrm{CSF} / \mathrm{serum}$ albumin ratio and MMSE scores across diagnosis groups and subgroups (classifications according to biochemical profiles, presence of pathological CSF/serum albumin ratio, and presence of prescriptions for vascular medicine) were tested in age and sex corrected ANCOVA models. Age corrected linear regression models were fitted for A $\beta 42, \mathrm{~T}$ tau, P-tau and NFL concentrations and CSF/serum albumin ratio in $\mathrm{AD}$. $\mathrm{Chi}^{2}$ statistics were used to analyze differences in proportions of patients with pathological vs. normal CSF/serum albumin ratios in each diagnosis group. Logarithmic transformations were applied to correct for significantly skewed data distributions. All statistics, charts and tables were produced in SPSS version 20 (IBM, New York).

\subsection{Ethics}

Patients and caretakers were informed orally and in writing about SveDem and could opt to decline participation and withdraw consent. This study was approved by the regional ethical boards at the University of Gothenburg and Lund University.

\section{Results}

\subsection{Demographics of study cohort}

Demographics of the study cohort can be found in Table 1. The EAD subjects were younger $(p<.001)$ than all other groups, and the FTD subjects were younger $(p<.001$ for NOS, LAD, VaD and MIX, $\mathrm{p}=.038$ for DLB) than all groups except EAD, PDD and other. The MIX 
subjects were older $(\mathrm{p}<.001)$ than all other groups except $\mathrm{VaD}$ and $\mathrm{PDD}$, and the $\mathrm{VaD}$ subjects were older $(\mathrm{p}<.001)$ than the LAD, EAD, FTD, NOS and other groups.

\subsection{CSF/serum albumin ratios across diagnosis groups}

$\mathrm{CSF} / \mathrm{serum}$ albumin ratios across the diagnostic groups are shown in Figure 1. The VaD group had higher CSF/serum albumin ratio than $\mathrm{HC1}$ (mean diff $=.26, \mathrm{p}<.001, \mathrm{SE}=.046$ ), HC2 $($ mean diff $=.33, \mathrm{p}=.001, \mathrm{SE}=.099), \mathrm{LAD}($ mean diff $=.09, \mathrm{p}=.017, \mathrm{SE}=.039)$, FTD $($ mean diff $=.20, \mathrm{p}=.002, \mathrm{SE}=.062), \mathrm{EAD}($ mean $\operatorname{diff}=.28, \mathrm{p}<.001, \mathrm{SE}=.055), \mathrm{PDD}$ (mean diff $=.22, \mathrm{p}=.02, \mathrm{SE}=.089)$ and $\operatorname{NOS}($ mean diff $=.10, \mathrm{p}=.016, \mathrm{SE}=.043)$. The LAD group had higher ratios than $\mathrm{HC} 1$ (mean diff $=.16, \mathrm{p}<.001, \mathrm{SE}=.041), \mathrm{HC} 2($ mean $\operatorname{diff}=.24, \mathrm{p}=.015, \mathrm{SE}=.096)$ and EAD $($ mean diff $=.19, \mathrm{p}<.001, \mathrm{SE}=.051)$. The MIX group had higher ratio than $\mathrm{HC} 1($ mean diff $=.21, \mathrm{p}<.001, \mathrm{SE}=.044), \mathrm{HC} 2($ mean diff $=$ $.287, \mathrm{p}=.003, \mathrm{SE}=.098), \mathrm{EAD}($ mean diff $=.24, \mathrm{p}<.001, \mathrm{SE}=.054)$ and FTD (mean diff $=$ $.16, \mathrm{p}=.011, \mathrm{SE}=.061)$. The NOS group had higher ratio than $\mathrm{HC} 1($ mean diff $=.15, \mathrm{p}=$ $.001, \mathrm{SE}=.045), \mathrm{HC} 2($ mean diff $=.23, \mathrm{p}=.022, \mathrm{SE}=.098)$ and $\mathrm{EAD}($ mean diff $=.18, \mathrm{p}=$ $.001, \mathrm{SE}=.055)$. The Other group had higher ratio than $\mathrm{HC} 1$ (mean diff $=.22, \mathrm{p}=.001, \mathrm{SE}=$ $.067), \mathrm{HC} 2($ mean diff $=.30, \mathrm{p}=.007, \mathrm{SE}=.110), \mathrm{EAD}($ mean diff $=.25, \mathrm{p}=.001, \mathrm{SE}=.074)$ and FTD (mean diff $=.17, \mathrm{p}=.037, \mathrm{SE}=.079)$. The DLB group had higher ratio than HC1 $($ mean diff $=.27, \mathrm{p}<.001, \mathrm{SE}=.069), \mathrm{HC} 2($ mean diff $=.35, \mathrm{p}=.002, \mathrm{SE}=.111), \mathrm{EAD}$ $($ mean diff $=.30, \mathrm{p}<.001, \mathrm{SE}=.075), \mathrm{FTD}($ mean diff $=.21, \mathrm{p}=.008, \mathrm{SE}=.081)$ and PDD (mean diff $=.23, \mathrm{p}=.024, \mathrm{SE}=.103)$. These comparisons were for logarithmic values and corrected for age and sex.

We also classified all subjects according to prevalence of pathologic CSF/serum albumin ratio. Proportions per diagnosis are shown in Figure 2. VaD had higher proportion of pathologic $\mathrm{CSF} /$ serum albumin ratio than $\mathrm{HC} 1, \mathrm{EAD}, \mathrm{FTD}, \mathrm{LAD}, \mathrm{MIX}$ and NOS $(\mathrm{p}<.05)$. LAD had a higher proportion than HC1 $(\mathrm{p}<.05)$. MIX had higher proportion than HC1, EAD 
and LAD $(\mathrm{p}<.05)$. NOS had higher proportion than HC1 and LAD $(\mathrm{p}<.05)$. Other had higher proportion than HC1, EAD, FTD and LAD $(\mathrm{p}<.05)$. DLB had higher proportion than HC1, EAD, FTD and LAD. All other differences were non-significant. The HC2 group had lower mean $\mathrm{CSF} /$ serum albumin value than all of the dementia diagnosis groups but the differences failed to reach significance.

\subsubsection{Correlations with biomarkers of neurodegeneration and $A \beta 42$}

$\mathrm{CSF} / \mathrm{serum}$ albumin ratio correlated with $\mathrm{A} \beta 42$ concentrations in $\operatorname{LAD}\left(\beta=.11, \mathrm{p}=.003, \mathrm{R}^{2}\right.$ $=.12)$, with T-tau in $\operatorname{MIX}\left(\beta=.15, \mathrm{p}=.003, \mathrm{R}^{2}=.14\right)$, and with $\mathrm{P}$-tau in $\operatorname{MIX}(\beta=.12, \mathrm{p}=$ $\left..013, \mathrm{R}^{2}=.14\right)$ and $\operatorname{VaD}\left(\beta=-.13, \mathrm{p}=.030, \mathrm{R}^{2}=.12\right) . \mathrm{CSF} /$ serum albumin ratio correlated with NFL concentrations in $\operatorname{LAD}\left(\beta=.24, \mathrm{p}<.001, \mathrm{R}^{2}=.17\right)$, MIX $\left(\beta=.21, \mathrm{p}<.001, \mathrm{R}^{2}=\right.$ $.17), \operatorname{NOS}\left(\beta=.25, p<.001, R^{2}=.21\right)$, Other $\left(\beta=.35, p=.41, R^{2}=.13\right)$ and $\operatorname{VaD}(\beta=.24$, $\left.\mathrm{p}<.001, \mathrm{R}^{2}=.15\right)$. All biomarker levels were on logarithmic scale.

\subsubsection{Disease severity}

To test associations between CSF/serum albumin ratio and cognitive impairment, we used MMSE as a proxy for clinical severity and tested associations between MMSE and presence of pathological CSF/serum albumin ratio. No significant differences between the two groups were found for any diagnosis, in age and sex corrected analyses.

\subsection{CSF/serum albumin ratio in $A D$}

\subsubsection{Biochemical profile}

The AD group (LAD + EAD + MIX) was split according to the IWG-2 guidelines into a biochemically positive AD group (IWG- $2+, \mathrm{n}=613$, median age $=75$ ) and a biochemically undetermined group (IWG-2-, $\mathrm{n}=545$, median age $=75$ ). There were no differences in $\mathrm{CSF} / \mathrm{serum}$ albumin ratio between the groups in an age and sex corrected analysis $(\mathrm{p}=.72)$. 


\subsubsection{Treatment for vascular risk factors}

We further sub-classified the AD group according to declared use of medications for cardiovascular co-morbidities ( $n=724$ on treatment vs. $n=434$ without treatment).

Cardiovascular drugs comprised antihypertensives, anticoagulants, lipid-lowering drugs, antidiabetics and anti-angina medication. Subjects with prescriptions had higher CSF/serum albumin ratio $(\mathrm{p}=.007$, mean diff $=.06)$. However, after age and sex correction, the presence of prescriptions no longer significantly predicted the $\mathrm{CSF} / \mathrm{serum}$ albumin ratio $(\mathrm{p}=.60)$.

\section{Discussion}

We tested CSF/serum albumin ratio, as a surrogate measure of BBB integrity, in patients with different dementia diagnoses to elucidate if certain diagnoses are associated with more BBB damage. We found that the $\mathrm{VaD}$, LAD, MIX, NOS, Other and DLB groups had higher CSF/serum albumin ratio than healthy controls. VaD in particular, but also DLB and MIX, had higher $\mathrm{CSF} /$ serum albumin ratio than the other groups. EAD had the lowest CSF/serum albumin ratio, although it should be noted that age correction cannot fully remove age as a confounder in the case of EAD vs. LAD as the age distributions in these groups do not overlap. Nevertheless, EAD were indistinguishable from similarly aged controls in terms of $\mathrm{CSF} / \mathrm{serum}$ albumin ratio. In addition, we investigated the relationship between CSF/serum albumin ratio and $\mathrm{AD}$ biomarkers and found that a positive biomarker profile for $\mathrm{AD}$ was not linked to more $\mathrm{BBB}$ damage. The $\mathrm{CSF} / \mathrm{serum}$ albumin ratio correlated positively with $\mathrm{CSF}$ NFL concentrations in $\mathrm{VaD}$, MIX, LAD, NOS and Other. This is consistent with the presence of leaking vessels, as reflected by increased CSF/serum ratio, and injury to myelinated axon, as reflected by increased NFL, in diseases with white matter changes. Taken together, these findings show that BBB damage is most evident in VaD but also occurs in LAD, MIX, NOS and Other. 


\subsection{Differences in BBB permeability in patients with different diagnoses of dementia}

$\mathrm{CSF} /$ serum albumin ratios were highest in the groups VaD, MIX, DLB and Other. The prevalence of pathological CSF/serum albumin ratio was higher in DLB, LAD, MIX, NOS, Other and $\mathrm{VaD}$ compared to $\mathrm{HC} 1$. Among these diagnoses, the prevalence of patients with pathological CSF/serum albumin ratio ranged from $10.5 \%$ in LAD to $26 \%$ in DLB, which is in accordance with a previous study showing a prevalence of pathological CSF/serum albumin ratio in $\mathrm{VaD}$ of $25 \%$ (Brettschneider et al., 2005). Importantly, the same study found that about $15 \%$ of patients receiving diagnostic lumbar puncture, who showed no other evidence of neurological disease had increased CSF/serum albumin ratio. Our healthy control groups combined showed a lower prevalence of pathological CSF/serum albumin ratio of $5.4 \%$ ( $5.1 \%$ and $10.0 \%$ in $\mathrm{HC} 1$ and $\mathrm{HC} 2$, respectively). Although rare, this shows that it is possible to have a slight BBB dysfunction, at least as reflected by the CSF/serum albumin ratio, without having significantly impaired cognition. This is also an inherent consequence of how reference limits are established in clinical chemistry; normality is defined by cut-points that define $95 \%$ of the tested individuals.

The higher prevalence of pathological CSF/serum albumin ratio in DLB compared to AD was in accordance with a previous study (Llorens et al., 2015). The prevalence of cerebrovascular lesions in DLB (De Reuck et al., 2013), which may lead to reduced CSF flow rate, could contribute to increased $\mathrm{CSF} /$ serum albumin ratio. Other studies using the SveDem data found that, despite a high burden of cerebrovascular disease, DLB patients have less diabetes mellitus than other dementia patients (Cermakova et al., 2015). Taken together with our findings of high prevalence of BBB damage in DLB but no correlation between NFL and $\mathrm{CSF} / \mathrm{serum}$ albumin ratio, this could indicate separate mechanisms of vascular pathology between DLB and VaD. 


\subsection{Increased BBB permeability is more prevalent in $\mathrm{VaD}$ than other dementia}

\section{diagnoses}

VaD patients had significantly higher CSF/serum albumin ratio than most other patients. This indicates that $\mathrm{BBB}$ disruption plays a part in, or reflects $\mathrm{VaD}$ pathophysiology, which has also been suggested in other studies (Blennow et al., 1990, Blennow et al., 1991, Farrall and Wardlaw, 2009, Skoog et al., 1998). A previous study showed that late stage PD patients without dementia had elevated CSF/serum albumin ratios (Pisani et al., 2012). However, we found no evidence of this, as the median CSF/serum albumin ratio did not increase with age in the PDD subjects in our cohort.

\subsection{Increased BBB permeability is more prominent in LAD than in EAD}

Post mortem neuropathological studies show degeneration of several important parts and functions of the BBB in AD (Halliday et al., 2016, Hultman et al., 2013, Sengillo et al., 2013). Similarly several other studies show increased occurrence of blood derived proteins in AD brains (Cortes-Canteli et al., 2010, Halliday et al., 2016, Hultman et al., 2013, Sengillo et al., 2013), and expression of the E4 isoform of apolipoprotein E, a strong genetic risk factor of developing AD (Hauser and Ryan, 2013, Michaelson, 2014), has been shown to lead to BBB breakdown in mice (Bell et al., 2012). Considering these reports, it is plausible that BBB integrity is compromised in some way in $\mathrm{AD}$. Although the role of $\mathrm{BBB}$ damage in $\mathrm{AD}$ has been disputed, a recent meta-analysis found no significant association of CSF/serum albumin ratio with $\mathrm{AD}$ (Olssonet al., 2016a). We found higher CSF/serum albumin ratio in LAD than in the control groups but no difference between the control groups and EAD. This may suggest increased BBB damage in LAD, but not in EAD. Pathological CSF/serum albumin ratios did not correlate with lower MMSE scores or IWG-2 positivity, and the CSF/serum albumin ratio correlated positively to $\mathrm{A} \beta 42$ levels. Taken together, our results indicate that $\mathrm{BBB}$ damage in $\mathrm{AD}$ is not primarily linked to $\mathrm{AD}$ pathology but rather to pathological 
vascular events that occur in LAD (Iturria-Medina et al., 2016). This is view further supported by the lack of difference in $\mathrm{CSF} /$ serum albumin ratio between EAD patients and age-matched controls in our study.

In contrast to our findings, studies using imaging techniques have found increased BBB leakage in EAD patients (van de Haar et al., 2016) and BBB damage in patients with mild cognitive impairment (Montagne et al., 2015). Indeed, using different techniques to measure BBB permeability will affect disease correlation. The conflicting results in this area are a testament to that BBB changes are subtle and large cohort sizes are important. Considering the different scopes of fluid biomarkers and imaging techniques, it may be beneficial to include both techniques in future studies of BBB damage in dementia patients. In addition, our data highlights that analyzing $\mathrm{AD}$ patients as one group or separated in to LAD and EAD can influence the outcome. The patient cohort in the study where $\mathrm{HC} 1$ was originally published is similar to our, however in that study LAD and EAD were analyzed as one AD group which was found to have increased BBB permeability compared to healthy controls (Janelidze et al., 2017). There are several similarities between our results and the results reported by Janelidze et al.; for example, the CSF/serum albumin ratio in DLB and VaD was found to be higher than in AD in both studies. In addition, the study by Janelidze et al. found that increased CSF/serum albumin ratio is independent of AD-related features such as amyloid pathology and APOE genotype. Similarly, we found that pathological CSF/serum albumin ratio in AD did not correlate with IWG-2 positivity. Our results suggest that BBB leakage in dementia may not be linked directly to $\mathrm{AD}$ pathology but rather to contaminant cerebral vascular pathology (Olsson et al., 2016b, Zhao et al., 2015).

CSF NFL concentrations correlated to the CSF/serum albumin ratio, as did declared use of medications for cardiovascular co-morbidities before correction for age and sex was 
introduced. CSF NFL correlates with white matter (WM) lesions in several conditions, and while AD patients show significant WM atrophy, which could lead to both elevated CSF NFL concentrations and CSF/serum albumin ratio, WM atrophy is more prominent and CSF NFL concentrations are considerably higher in VaD (Blennowet al., 1991, Jonsson et al., 2010, Lycke et al., 1998, Sjogren et al., 2001, Skillback et al., 2014, Zanier et al., 2011). Taken together, these results might stem from contaminant cerebral vascular pathology and a relative rarity of biochemically pure $\mathrm{AD}$, but could also indicate abundance of WM lesions (Attems and Jellinger, 2014, McAleese et al., 2016). Further studies are required to understand the extent of the overlap between $\mathrm{AD}$ and $\mathrm{VaD}$. The MIX group had a large proportion of patients with pathological CSF/albumin ratios and a positive correlation between CSF NFL concentration and CSF/albumin ratio, consistent with the notion of concomitant $\mathrm{VaD}$ as a driving force of $\mathrm{BBB}$ damage in $\mathrm{AD}$, corroborating previous studies (Hermann et al., 2014).

\subsection{Strengths and Limitations}

The main strength of this study was the large cohort size, the broad referral base and the wide range of dementia diagnoses represented. The main limitation is the lack of detailed clinical data, for example $A P O E$ genotype and post-mortem diagnosis confirmation. In addition, we did not test different subtypes of $\mathrm{VaD}$, which have distinct effects on $\mathrm{BBB}$ integrity (McAleese et al., 2016). Further, some researchers caution against describing the CSF/serum albumin ratio as a BBB test and state that it actually reflects the blood-CSF barrier at the choroid plexus (Reiber and Peter, 2001). However, in for example stroke, leaving the choroid plexus intact but injuring cerebrovascular endothelial cells, the CSF/serum albumin ratio may be increased (Brouns et al., 2011), suggesting that albumin ratio probably is a marker of both barriers. Albumin levels may also be affected by other factors for which we lack information, such as cleavage, degradation or uptake by microglia, astrocytes, pericytes and NG2-positive cells, or presence of spinal stenosis or other deformations affecting the flow rate of CSF 
(Braganza et al., 2012, Ivens et al., 2007, LeVine, 2016). Another limitation was the use of MMSE as a measure of disease severity, as MMSE is a test primarily designed to measure cognitive decline due to $\mathrm{AD}$ and hippocampal dysfunction, and is not an ideal test for cognitive decline due to VaD, FTD, DLB or PDD (Hodges et al., 1999, Palmqvist et al., 2009, Prieto et al., 2011). A previous study has indicated that measures of executive function might be more closely linked to BBB integrity in VaD, MIX and AD (Hermann et al., 2014).

\subsection{Conclusions}

Our results indicate that BBB permeability is increased in dementia patients compared to healthy controls, with increased CSF/serum albumin ratio primarily in DLB, LAD, VaD, MIX, Others and NOS. The influence of BBB function impairment is most prominent in VaD, DLB, MIX Other and NOS, and more prominent in LAD than in EAD. The results suggest that $\mathrm{BBB}$ leakage in $\mathrm{AD}$ may be a consequence of contaminant cerebrovascular pathology rather than the $\mathrm{AD}$ process per se. 


\section{Funding}

The study was supported by the Swedish Research Council [grant number 2013-2546], the European Research Council [grant number 681712], Swedish State Support for Clinical Research [grant number ALFGBG-441051], the Knut and Alice Wallenberg Foundation, the Swedish Brain Foundation [grant number FO2015-0021], the Torsten Söderberg Foundation, Frimurarestiftelsen, Stiftelsen Gamla Tjänarinnor, Alzheimerfonden [Grant number AF646211], Skåne University Hospital (SUS) Foundations and Donations, the Swedish Knowledge Foundation [grant number 2014-0298] and the Swedish Associations of Local Authorities and Regions.

\section{Acknowledgements}

The authors are grateful to the national Swedish Dementia Registry (SveDem, www.svedem.se) and thank all patients and caregivers, reporting units and regional coordinators for providing data for this study. We thank the Swedish Brain Power programme for their support.

\section{Disclosure statement}

The authors wish to confirm that there are no known conflicts of interest associated with the publication of this manuscript. 


\section{References}

Alafuzoff I, Adolfsson R, Bucht G, Winblad B. Albumin and immunoglobulin in plasma and cerebrospinal fluid, and blood-cerebrospinal fluid barrier function in patients with dementia of Alzheimer type and multi-infarct dementia. Journal of the neurological sciences 1983;60(3):465-72.

Attems J, Jellinger KA. The overlap between vascular disease and Alzheimer's disease - lessons from pathology. BMC medicine 2014;12(1):206.

Bell RD, Winkler EA, Singh I, Sagare AP, Deane R, Wu Z, Holtzman DM, Betsholtz C, Armulik A, Sallstrom J, Berk BC, Zlokovic BV. Apolipoprotein E controls cerebrovascular integrity via cyclophilin A. Nature 2012;485(7399):512-6.

Beydoun MA, Beydoun HA, Gamaldo AA, Teel A, Zonderman AB, Wang Y. Epidemiologic studies of modifiable factors associated with cognition and dementia: systematic review and metaanalysis. BMC Public Health 2014;14:643-.

Bien-Ly N, Boswell CA, Jeet S, Beach TG, Hoyte K, Luk W, Shihadeh V, Ulufatu S, Foreman O, Lu Y, DeVoss J, van der Brug M, Watts RJ. Lack of Widespread BBB Disruption in Alzheimer's Disease Models: Focus on Therapeutic Antibodies. Neuron 2015;88(2):289-97.

Blair L, Frauen HD, Zhang B, Nordhues BA, Bijan S, Lin YC, Zamudio F, Hernandez LD, Sabbagh JJ, Selenica ML, Dickey CA. Tau depletion prevents progressive blood-brain barrier damage in a mouse model of tauopathy. Acta neuropathologica communications 2015;3:8.

Blennow K, Wallin A, Fredman P, Karlsson I, Gottfries CG, Svennerholm L. Blood-brain barrier disturbance in patients with Alzheimer's disease is related to vascular factors. Acta neurologica Scandinavica 1990;81(4):323-6.

Blennow K, Wallin A, Uhlemann C, Gottfries CG. White-matter lesions on CT in Alzheimer patients: relation to clinical symptomatology and vascular factors. Acta neurologica Scandinavica 1991;83(3):187-93.

Braganza O, Bedner P, Huttmann K, von Staden E, Friedman A, Seifert G, Steinhauser C. Albumin is taken up by hippocampal NG2 cells and astrocytes and decreases gap junction coupling. Epilepsia 2012;53(11):1898-906.

Brettschneider J, Claus A, Kassubek J, Tumani H. Isolated blood-cerebrospinal fluid barrier dysfunction: prevalence and associated diseases. Journal of neurology 2005;252(9):1067-73.

Bridges LR, Andoh J, Lawrence AJ, Khoong CHL, Poon W, Esiri MM, Markus HS, Hainsworth AH. BloodBrain Barrier Dysfunction and Cerebral Small Vessel Disease (Arteriolosclerosis) in Brains of Older People. Journal of neuropathology and experimental neurology 2014;73(11):1026-33.

Brouns R, Wauters A, De Surgeloose D, Marien P, De Deyn PP. Biochemical markers for blood-brain barrier dysfunction in acute ischemic stroke correlate with evolution and outcome. European neurology 2011;65(1):23-31.

Cermakova P, Johnell K, Fastbom J, Garcia-Ptacek S, Lund LH, Winblad B, Eriksdotter M, Religa D. Cardiovascular Diseases in $\sim 30,000$ Patients in the Swedish Dementia Registry. Journal of Alzheimer's disease : JAD 2015;48(4):949-58.

Cortes-Canteli M, Paul J, Norris EH, Bronstein R, Ahn HJ, Zamolodchikov D, Bhuvanendran S, Fenz KM, Strickland S. Fibrinogen and beta-amyloid association alters thrombosis and fibrinolysis: a possible contributing factor to Alzheimer's disease. Neuron 2010;66(5):695-709.

De Reuck J, Deramecourt V, Cordonnier C, Leys D, Pasquier F, Maurage CA. Prevalence of cerebrovascular lesions in patients with Lewy body dementia: a neuropathological study. Clinical neurology and neurosurgery 2013;115(7):1094-7.

Dubois B, Feldman HH, Jacova C, Hampel H, Molinuevo JL, Blennow K, DeKosky ST, Gauthier S, Selkoe D, Bateman R, Cappa S, Crutch S, Engelborghs S, Frisoni GB, Fox NC, Galasko D, Habert MO, Jicha GA, Nordberg A, Pasquier F, Rabinovici G, Robert P, Rowe C, Salloway S, Sarazin M, Epelbaum S, de Souza LC, Vellas B, Visser PJ, Schneider L, Stern Y, Scheltens P, Cummings JL. 
Advancing research diagnostic criteria for Alzheimer's disease: the IWG-2 criteria. Lancet Neurol 2014;13(6):614-29.

Elovaara I, Maury CP, Palo J. Serum amyloid A protein, albumin and prealbumin in Alzheimer's disease and in demented patients with Down's syndrome. Acta neurologica Scandinavica 1986;74(3):245-50.

Farrall AJ, Wardlaw JM. Blood-brain barrier: ageing and microvascular disease--systematic review and meta-analysis. Neurobiology of aging 2009;30(3):337-52.

Felgenhauer K, Renner E. Hydrodynamic radii versus molecular weights in clearance studies of urine and cerebrospinal fluid. Annals of clinical biochemistry 1977;14(2):100-4.

Fornari E, Maeder P, Meuli R, Ghika J, Knyazeva MG. Demyelination of superficial white matter in early Alzheimer's disease: a magnetization transfer imaging study. Neurobiology of aging 2012;33(2):428.e7-19.

Gama Sosa MA, Gasperi RD, Rocher AB, Wang AC, Janssen WG, Flores T, Perez GM, Schmeidler J, Dickstein DL, Hof PR, Elder GA. Age-related vascular pathology in transgenic mice expressing presenilin 1-associated familial Alzheimer's disease mutations. The American journal of pathology 2010;176(1):353-68.

Giannoni P, Arango-Lievano M, Neves ID, Rousset MC, Baranger K, Rivera S, Jeanneteau F, Claeysen S, Marchi N. Cerebrovascular pathology during the progression of experimental Alzheimer's disease. Neurobiology of disease 2016;88:107-17.

Gorelick PB. Risk factors for vascular dementia and Alzheimer disease. Stroke; a journal of cerebral circulation 2004;35(11 Suppl 1):2620-2.

Halliday MR, Rege SV, Ma Q, Zhao Z, Miller CA, Winkler EA, Zlokovic BV. Accelerated pericyte degeneration and blood-brain barrier breakdown in apolipoprotein E4 carriers with Alzheimer's disease. Journal of cerebral blood flow and metabolism : official journal of the International Society of Cerebral Blood Flow and Metabolism 2016;36(1):216-27.

Hampel H, Kotter HU, Moller HJ. Blood-cerebrospinal fluid barrier dysfunction for high molecular weight proteins in Alzheimer disease and major depression: indication for disease subsets. Alzheimer disease and associated disorders 1997;11(2):78-87.

Hauser PS, Ryan RO. Impact of apolipoprotein E on Alzheimer's disease. Current Alzheimer research 2013;10(8):809-17.

Hayden KM, Zandi PP, Lyketsos CG, Khachaturian AS, Bastian LA, Charoonruk G, Tschanz JT, Norton MC, Pieper CF, Munger RG, Breitner JCS, Welsh-Bohmer KA. Vascular risk factors for incident Alzheimer disease and vascular dementia: The Cache County Study. Alzheimer disease and associated disorders 2006;20(2):93-100.

Hermann P, Romero C, Schmidt C, Reis C, Zerr I. CSF biomarkers and neuropsychological profiles in patients with cerebral small-vessel disease. PloS one 2014;9(8):e105000.

Hodges JR, Patterson K, Ward R, Garrard P, Bak T, Perry R, Gregory C. The differentiation of semantic dementia and frontal lobe dementia (temporal and frontal variants of frontotemporal dementia) from early Alzheimer's disease: a comparative neuropsychological study. Neuropsychology 1999;13(1):31-40.

Hovsepyan MR, Haas MJ, Boyajyan AS, Guevorkyan AA, Mamikonyan AA, Myers SE, Mooradian AD. Astrocytic and neuronal biochemical markers in the sera of subjects with diabetes mellitus. Neuroscience letters 2004;369(3):224-7.

Hsu TM, Kanoski SE. Blood-brain barrier disruption: mechanistic links between Western diet consumption and dementia. Frontiers in Aging Neuroscience 2014;6:88.

Hughes TF, Ganguli M. Modifiable Midlife Risk Factors for Late-Life Cognitive Impairment and Dementia. Current psychiatry reviews 2009;5(2):73-92.

Hultman K, Strickland S, Norris EH. The APOE varepsilon4/varepsilon4 genotype potentiates vascular fibrin(ogen) deposition in amyloid-laden vessels in the brains of Alzheimer's disease patients. Journal of cerebral blood flow and metabolism : official journal of the International Society of Cerebral Blood Flow and Metabolism 2013;33(8):1251-8.

ladecola C. The pathobiology of vascular dementia. Neuron 2013;80(4):844-66. 
Iturria-Medina Y, Sotero RC, Toussaint PJ, Mateos-Perez JM, Evans AC. Early role of vascular dysregulation on late-onset Alzheimer's disease based on multifactorial data-driven analysis. Nature communications 2016;7:11934.

Ivens S, Kaufer D, Flores LP, Bechmann I, Zumsteg D, Tomkins O, Seiffert E, Heinemann U, Friedman A. TGF-beta receptor-mediated albumin uptake into astrocytes is involved in neocortical epileptogenesis. Brain : a journal of neurology 2007;130(Pt 2):535-47.

Janelidze S, Hertze J, Nagga K, Nilsson K, Nilsson C, Wennstrom M, van Westen D, Blennow K, Zetterberg $\mathrm{H}$, Hansson $\mathrm{O}$. Increased blood-brain barrier permeability is associated with dementia and diabetes but not amyloid pathology or APOE genotype. Neurobiology of aging 2017;51:104-12.

Johansson P, Mattsson N, Hansson O, Wallin A, Johansson JO, Andreasson U, Zetterberg H, Blennow $\mathrm{K}$, Svensson J. Cerebrospinal fluid biomarkers for Alzheimer's disease: diagnostic performance in a homogeneous mono-center population. Journal of Alzheimer's disease : JAD 2011;24(3):537-46.

Jonsson M, Zetterberg H, van Straaten E, Lind K, Syversen S, Edman A, Blennow K, Rosengren L, Pantoni L, Inzitari D, Wallin A. Cerebrospinal fluid biomarkers of white matter lesions - crosssectional results from the LADIS study. European journal of neurology : the official journal of the European Federation of Neurological Societies 2010;17(3):377-82.

Kay AD, May C, Papadopoulos NM, Costello R, Atack JR, Luxenberg JS, Cutler NR, Rapoport SI. CSF and serum concentrations of albumin and IgG in Alzheimer's disease. Neurobiology of aging 1987;8(1):21-5.

Kilander L, Andren B, Nyman H, Lind L, Boberg M, Lithell H. Atrial fibrillation is an independent determinant of low cognitive function: a cross-sectional study in elderly men. Stroke; a journal of cerebral circulation 1998;29(9):1816-20.

Kivipelto M, Helkala EL, Laakso MP, Hanninen T, Hallikainen M, Alhainen K, Soininen H, Tuomilehto J, Nissinen A. Midlife vascular risk factors and Alzheimer's disease in later life: longitudinal, population based study. BMJ (Clinical research ed) 2001;322(7300):1447-51.

Kumar-Singh S, Pirici D, McGowan E, Serneels S, Ceuterick C, Hardy J, Duff K, Dickson D, Van Broeckhoven C. Dense-core plaques in Tg2576 and PSAPP mouse models of Alzheimer's disease are centered on vessel walls. The American journal of pathology 2005;167(2):527-43.

LeVine SM. Albumin and multiple sclerosis. BMC neurology 2016;16:47.

Llorens F, Schmitz M, Gloeckner SF, Kaerst L, Hermann P, Schmidt C, Varges D, Zerr I. Increased albumin CSF/serum ratio in dementia with Lewy bodies. Journal of the neurological sciences 2015;358(1-2):398-403.

Lycke JN, Karlsson JE, Andersen O, Rosengren LE. Neurofilament protein in cerebrospinal fluid: a potential marker of activity in multiple sclerosis. Journal of neurology, neurosurgery, and psychiatry 1998;64(3):402-4.

Martinez-Martin P, Falup-Pecurariu C, Rodriguez-Blazquez C, Serrano-Duenas M, Carod Artal FJ, Rojo Abuin JM, Aarsland D. Dementia associated with Parkinson's disease: applying the Movement Disorder Society Task Force criteria. Parkinsonism \& related disorders 2011;17(8):621-4.

McAleese KE, Alafuzoff I, Charidimou A, De Reuck J, Grinberg LT, Hainsworth AH, Hortobagyi T, Ince P, Jellinger K, Gao J, Kalaria RN, Kovacs GG, Kövari E, Love S, Popovic M, Skrobot O, Taipa R, Thal DR, Werring D, Wharton SB, Attems J. Post-mortem assessment in vascular dementia: advances and aspirations. BMC medicine 2016;14(1):129.

McKeith IG, Dickson DW, Lowe J, Emre M, O'Brien JT, Feldman H, Cummings J, Duda JE, Lippa C, Perry EK, Aarsland D, Arai H, Ballard CG, Boeve B, Burn DJ, Costa D, Del Ser T, Dubois B, Galasko D, Gauthier S, Goetz CG, Gomez-Tortosa E, Halliday G, Hansen LA, Hardy J, Iwatsubo T, Kalaria RN, Kaufer D, Kenny RA, Korczyn A, Kosaka K, Lee VM, Lees A, Litvan I, Londos E, Lopez OL, Minoshima S, Mizuno Y, Molina JA, Mukaetova-Ladinska EB, Pasquier F, Perry RH, Schulz JB, Trojanowski JQ, Yamada M, Consortium on DLB. Diagnosis and management of dementia with Lewy bodies: third report of the DLB Consortium. Neurology 2005;65(12):1863-72. 
Michaelson DM. APOE epsilon4: the most prevalent yet understudied risk factor for Alzheimer's disease. Alzheimer's \& dementia : the journal of the Alzheimer's Association 2014;10(6):8618.

Montagne A, Barnes SR, Sweeney MD, Halliday MR, Sagare AP, Zhao Z, Toga AW, Jacobs RE, Liu CY, Amezcua L, Harrington MG, Chui HC, Law M, Zlokovic BV. Blood-brain barrier breakdown in the aging human hippocampus. Neuron 2015;85(2):296-302.

Nelson AR, Sweeney MD, Sagare AP, Zlokovic BV. Neurovascular dysfunction and neurodegeneration in dementia and Alzheimer's disease. Biochim Biophys Acta 2016;1862(5):887-900.

Obermeier B, Daneman R, Ransohoff RM. Development, maintenance and disruption of the bloodbrain barrier. Nature medicine 2013;19(12):1584-96.

Olsson B, Lautner R, Andreasson U, Ohrfelt A, Portelius E, Bjerke M, Holtta M, Rosen C, Olsson C, Strobel G, Wu E, Dakin K, Petzold M, Blennow K, Zetterberg H. CSF and blood biomarkers for the diagnosis of Alzheimer's disease: a systematic review and meta-analysis. Lancet neurology 2016a.

Olsson B, Lautner R, Andreasson U, Ohrfelt A, Portelius E, Bjerke M, Holtta M, Rosen C, Olsson C, Strobel G, Wu E, Dakin K, Petzold M, Blennow K, Zetterberg H. CSF and blood biomarkers for the diagnosis of Alzheimer's disease: a systematic review and meta-analysis. The Lancet Neurology 2016b;15(7):673-84.

Ott A, Stolk RP, Hofman A, van Harskamp F, Grobbee DE, Breteler MM. Association of diabetes mellitus and dementia: the Rotterdam Study. Diabetologia 1996;39(11):1392-7.

Palmqvist S, Hansson O, Minthon L, Londos E. Practical suggestions on how to differentiate dementia with Lewy bodies from Alzheimer's disease with common cognitive tests. International journal of geriatric psychiatry 2009;24(12):1405-12.

Pan R, Yu K, Weatherwax T, Zheng H, Liu W, Liu KJ. Blood Occludin Level as a Potential Biomarker for Early Blood Brain Barrier Damage Following Ischemic Stroke. Scientific reports 2017;7:40331.

Park L, Zhou J, Zhou P, Pistick R, El Jamal S, Younkin L, Pierce J, Arreguin A, Anrather J, Younkin SG, Carlson GA, McEwen BS, ladecola C. Innate immunity receptor CD36 promotes cerebral amyloid angiopathy. Proceedings of the National Academy of Sciences of the United States of America 2013;110(8):3089-94.

Pisani V, Stefani A, Pierantozzi M, Natoli S, Stanzione P, Franciotta D, Pisani A. Increased bloodcerebrospinal fluid transfer of albumin in advanced Parkinson's disease. Journal of neuroinflammation 2012;9:188.

Prieto G, Delgado AR, Perea MV, Ladera V. Differential functioning of mini-mental test items according to disease. Neurologia (Barcelona, Spain) 2011;26(8):474-80.

Reiber H, Peter JB. Cerebrospinal fluid analysis: disease-related data patterns and evaluation programs. Journal of the neurological sciences 2001;184(2):101-22.

Religa D, Fereshtehnejad SM, Cermakova P, Edlund AK, Garcia-Ptacek S, Granqvist N, Hallback A, Kawe K, Farahmand B, Kilander L, Mattsson UB, Nagga K, Nordstrom P, Wijk H, Wimo A, Winblad B, Eriksdotter M. SveDem, the Swedish Dementia Registry - a tool for improving the quality of diagnostics, treatment and care of dementia patients in clinical practice. PloS one 2015;10(2):e0116538.

Ryu JK, Petersen MA, Murray SG, Baeten KM, Meyer-Franke A, Chan JP, Vagena E, Bedard C, Machado MR, Rios Coronado PE, Prod'homme T, Charo IF, Lassmann H, Degen JL, Zamvil SS, Akassoglou K. Blood coagulation protein fibrinogen promotes autoimmunity and demyelination via chemokine release and antigen presentation. Nat Commun 2015;6:8164.

Sengillo JD, Winkler EA, Walker CT, Sullivan JS, Johnson M, Zlokovic BV. Deficiency in mural vascular cells coincides with blood-brain barrier disruption in Alzheimer's disease. Brain pathology (Zurich, Switzerland) 2013;23(3):303-10.

Sjogren $M$, Blomberg $M$, Jonsson $M$, Wahlund LO, Edman A, Lind K, Rosengren L, Blennow K, Wallin A. Neurofilament protein in cerebrospinal fluid: a marker of white matter changes. Journal of neuroscience research 2001;66(3):510-6. 
Skillback T, Farahmand B, Bartlett JW, Rosen C, Mattsson N, Nagga K, Kilander L, Religa D, Wimo A, Winblad B, Rosengren L, Schott JM, Blennow K, Eriksdotter M, Zetterberg H. CSF neurofilament light differs in neurodegenerative diseases and predicts severity and survival. Neurology 2014;83(21):1945-53.

Skoog I, Lernfelt B, Landahl S, Palmertz B, Andreasson LA, Nilsson L, Persson G, Oden A, Svanborg A. 15-year longitudinal study of blood pressure and dementia. Lancet (London, England) 1996;347(9009):1141-5.

Skoog I, Wallin A, Fredman P, Hesse C, Aevarsson O, Karlsson I, Gottfries CG, Blennow K. A population study on blood-brain barrier function in 85-year-olds: relation to Alzheimer's disease and vascular dementia. Neurology 1998;50(4):966-71.

Sorbi S, Hort J, Erkinjuntti T, Fladby T, Gainotti G, Gurvit H, Nacmias B, Pasquier F, Popescu BO, Rektorova I, Religa D, Rusina R, Rossor M, Schmidt R, Stefanova E, Warren JD, Scheltens $P$, Dementia ESPo, Cognitive N. EFNS-ENS Guidelines on the diagnosis and management of disorders associated with dementia. European journal of neurology : the official journal of the European Federation of Neurological Societies 2012;19(9):1159-79.

Starr J, Wardlaw J, Ferguson K, MacLullich A, Deary I, Marshall I. Increased blood-brain barrier permeability in type II diabetes demonstrated by gadolinium magnetic resonance imaging. Journal of Neurology, Neurosurgery, and Psychiatry 2003;74(1):70-6.

SveDem. About SveDem, Swedish Dementia Registry, http://www.ucr.uu.se/svedem/index.php/about-svedem; 2015 [accessed 2016-12-12.2015].

Sweeney MD, Sagare AP, Zlokovic BV. Cerebrospinal fluid biomarkers of neurovascular dysfunction in mild dementia and Alzheimer's disease. Journal of cerebral blood flow and metabolism : official journal of the International Society of Cerebral Blood Flow and Metabolism 2015;35(7):1055-68.

Taheri S, Gasparovic C, Huisa BN, Adair JC, Edmonds E, Prestopnik J, Grossetete M, Shah NJ, Wills J, Qualls C, Rosenberg GA. Blood-brain barrier permeability abnormalities in vascular cognitive impairment. Stroke; a journal of cerebral circulation 2011;42(8):2158-63.

Tang JP, Rakhit A, Douglas FL, Melethil S. Effect of chronic hypertension on the blood-brain barrier permeability of libenzapril. Pharmaceutical research 1992;9(2):236-43.

The Lund and Manchester Groups. Clinical and neuropathological criteria for frontotemporal dementia. The Lund and Manchester Groups. Journal of neurology, neurosurgery, and psychiatry 1994;57(4):416-8.

Tibbling G, Link H, Öhman S. Principles of albumin and IgG analyses in neurological disorders. I. Establishment of reference values. Scandinavian Journal of Clinical and Laboratory Investigation 1977;37(5):385-90.

Wada H. Blood-brain barrier permeability of the demented elderly as studied by cerebrospinal fluidserum albumin ratio. Internal medicine (Tokyo, Japan) 1998;37(6):509-13.

van de Haar HJ, Burgmans S, Jansen JF, van Osch MJ, van Buchem MA, Muller M, Hofman PA, Verhey FR, Backes WH. Blood-Brain Barrier Leakage in Patients with Early Alzheimer Disease. Radiology 2016:152244.

Waubant E, Goodkin DE, Gee L, Bacchetti P, Sloan R, Stewart T, Andersson PB, Stabler G, Miller K. Serum MMP-9 and TIMP-1 levels are related to MRI activity in relapsing multiple sclerosis. Neurology 1999;53(7):1397-401.

Wiesmann M, Kiliaan AJ, Claassen JAHR. Vascular aspects of cognitive impairment and dementia. Journal of Cerebral Blood Flow \& Metabolism 2013;33(11):1696-706.

Wimo A, Guerchet M, Ali GC, Wu YT, Prina AM, Winblad B, Jonsson L, Liu Z, Prince M. The worldwide costs of dementia 2015 and comparisons with 2010. Alzheimer's \& dementia : the journal of the Alzheimer's Association 2017;13(1):1-7.

World Health Organization. The ICD-10 classification of mental and behavioural disorders : diagnostic criteria for research. Geneva: World Health Organization, 1993. xiii, 248 p. p.

Zanier ER, Refai D, Zipfel GJ, Zoerle T, Longhi L, Esparza TJ, Spinner ML, Bateman RJ, Brody DL, Stocchetti N. Neurofilament light chain levels in ventricular cerebrospinal fluid after acute 
aneurysmal subarachnoid haemorrhage. Journal of neurology, neurosurgery, and psychiatry 2011;82(2):157-9.

Zhao Z, Nelson AR, Betsholtz C, Zlokovic BV. Establishment and Dysfunction of the Blood-Brain Barrier. Cell 2015;163(5):1064-78. 


\section{Figure legends}

Figure 1. CSF/serum albumin ratio per diagnosis

Median and IQR levels of CSF/serum albumin ratio. Observed data are shown here; see main text for comparisons adjusted for age and sex. Dashed lines indicate thresholds for albumin quotient pathology for 30-49 year olds (orange) and >50 year olds (red). VaD, MIX and DLB have the highest CSF/serum albumin ratios while the healthy control groups and EAD have lower CSF/serum albumin ratios.

Figure 2. CSF/serum albumin ratio pathology proportions per diagnosis Pathologic albumin quotients are most common in DLB, Other, VaD and MIX. 
Table 1. Demographics and CSF/serum albumin ratio in all diagnostic groups

\begin{tabular}{|c|c|c|c|c|c|c|c|c|c|c|c|c|c|}
\hline \multicolumn{3}{|l|}{ Diagnosis } & HC1 & HC2 & LAD & EAD & MIX & VAD & FTD & DLB & PDD & Other & NOS \\
\hline \multicolumn{3}{|l|}{$\mathbf{N}$} & 292 & 20 & 666 & 130 & 362 & 255 & 56 & 50 & 23 & 48 & 271 \\
\hline \multirow{2}{*}{\multicolumn{2}{|c|}{ Sex }} & $F(\%)$ & 60 & 50 & 448 (67\%) & 81 (62\%) & 210 (58\%) & 110 (43\%) & 29 (52\%) & $14(28 \%)$ & $6(26 \%)$ & 23 (48\%) & 144 (53\%) \\
\hline & & M (\%) & 40 & 50 & 218 (33\%) & 49 (38\%) & $152(42 \%)$ & 145 (57\%) & 27 (48\%) & 36 (72\%) & $17(74 \%)$ & $25(52 \%)$ & $127(47 \%)$ \\
\hline \multirow{2}{*}{\multicolumn{2}{|c|}{ Age at sampling }} & Mean (SD) & $73(5)$ & $74(5)$ & $75(6)$ & $59(4)$ & 79 (7) & $77(8)$ & $67(10)$ & $73(7)$ & $73(8)$ & $72(10)$ & 74 (9) \\
\hline & & Mdn (IQR) & 73 (69-76) & 75 (71-78) & $75(71-80)$ & $60(56-62)$ & 79 (74-84) & $78(72-83)$ & $65(60-74)$ & 74 (69-79) & 73 (68-78) & $73(65-80)$ & $75(68-80)$ \\
\hline \multirow{2}{*}{\multicolumn{2}{|c|}{ MMSE }} & Mean (SD) & $29(1)$ & $28(2)$ & $22(5)$ & $22(5)$ & $22(5)$ & $22(4)$ & $25(5)$ & $22(5)$ & $24(4)$ & $23(5)$ & $22(5)$ \\
\hline & & Mdn (IQR) & $29(29-30)$ & $29(27-29)$ & $23(20-26)$ & $22(18-25)$ & $23(19-25)$ & $22(20-25)$ & $26(23-28)$ & $22(20-25)$ & $27(22-28)$ & $25(20-27)$ & $23(20-26)$ \\
\hline \multirow{2}{*}{\multicolumn{2}{|c|}{ Albumin quotient }} & Mean (SD) & $5.9(2.2)$ & $5.9(2.4)$ & $6.8(2.7)$ & $6.8(7.6)$ & $7.7(3.4)$ & $8.9(8.2)$ & $6.5(2.4)$ & $8.4(4.3)$ & $6.6(2.4)$ & $8(3.8)$ & $7.4(3.4)$ \\
\hline & & Mdn (IQR) & $5.8(4.3-7.0)$ & $5.5(3.9-7.8)$ & $6.3(4.9-8.2)$ & $5.4(4.1-7.7)$ & $7.3(5.4-9.0)$ & $7.6(5.6-10.1)$ & $6.5(4.6-7.8)$ & $7.4(5.6-10.5)$ & $6.1(4.7-8.8)$ & $7.3(5.1-9.6)$ & $6.6(5.1-8.8)$ \\
\hline Age stratified & -50 & $\operatorname{Mdn}(N)$ & (0) & (0) & (0) & $5.1(4)$ & (0) & (0) & $7.3(2)$ & (0) & (0) & $9.9(1)$ & $5.2(1)$ \\
\hline \multicolumn{14}{|l|}{ Alb quotients } \\
\hline & $51-60$ & $\operatorname{Mdn}(\mathrm{N})$ & (0) & (0) & (0) & $5.5(68)$ & $6(3)$ & 7.4 (13) & 4.7 (13) & $7.8(2)$ & $6.1(1)$ & $7.1(4)$ & $6.7(17)$ \\
\hline & $61-70$ & $\operatorname{Mdn}(N)$ & $5.3(109)$ & $5.8(5)$ & $5.9(164)$ & $5.3(58)$ & $6.5(53)$ & $7.1(31)$ & $6.2(24)$ & $8.2(14)$ & $6.5(6)$ & $5.1(16)$ & $6.2(69)$ \\
\hline & $71-80$ & $\operatorname{Mdn}(\mathrm{N})$ & $5.8(157)$ & 5.5 (14) & $6.1(353)$ & (0) & 7.3 (149) & $7.9(116)$ & $6.9(12)$ & $7(27)$ & $6(13)$ & $8.3(18)$ & $6.9(120)$ \\
\hline & $81-90$ & $\operatorname{Mdn}(\mathrm{N})$ & $6.3(26)$ & $2.8(1)$ & 7.5 (148) & (0) & $7.4(148)$ & $7.5(92)$ & $7.8(5)$ & $7.6(7)$ & $5.8(3)$ & $6.7(9)$ & $6.7(61)$ \\
\hline & $90+$ & $\operatorname{Mdn}(N)$ & (0) & (0) & $4.4(1)$ & (0) & $9.6(9)$ & 6.9 (3) & (0) & (0) & (0) & (0) & $6.4(3)$ \\
\hline
\end{tabular}

